JOURNAL OF MECHANICAL ENGINEERING, MANUFACTURES, MATERIALS AND ENERGY

Doi: $10.31289 /$ jmemme.v5i2.4926

Available online http://ojs.uma.ac.id/index.php/jmemme

\title{
Analisis Kerusakan Main Bearing pada Unit Generator Mitsubishi BMGS
}

\section{Analysis of Damage to Main Bearings in Unit of BMGS Mitsubishi Generator}

\author{
Wilarso Arso1)*, Aswin Domodite ${ }^{2)}$ \\ 1,2 Sekolah Tinggi Teknologi Muhammadiyah Cileungsi
}

Diterima: 23-02-2021 ; Disetujui: 24-07-2021 ; Diterbitkan: 30-12-2021

*Corresponding author: E-mail: wilarso09@gmail.com

\begin{abstract}
Abstrak
Kerusakan pada komponen main bearing pada unit generator set yang beroperasi di PLTD untuk mensuplai daya ke PLN. Berdasarkan dari indikasi awal engine blow by dan high vibration pada damper area pada service meter unit (SMU): 25555. Tujuan dalam penelitian ini untuk menentukan akar penyebab dari kerusakan main bearing yang mengalami perubahan bentuk dan warna pada diesel engine generator set. Metode yang dilakukan dalam penelitian ini visual inspeksi dan melepas komponen engine. Hasil dan pembahasan dari penelitian didapat perubahan bentuk dan warna pada main bearing, berawal dari material main bearing (berputar) spalling, sehingga bergesekan dengan main journal. Gesekan yang terjadi mengakibatkan perubahan bentuk pada main bearing dan mengakibatkan main bearing berputar. Keyword pada main bearing terlepas karena terjadi penipisan, sehingga main bearing berputar dan menutup suplai pelumasan oli ke main dan rod bearing. Berdasarkan analisis, penyebab dari adhesive wear pada Main Bearing \#1 yang paling memungkinkan adalah misalignment crankshaft ke arah depan engine.
\end{abstract}

Kata kunci: Generator set, Main bearing, Perubahan Bentuk, Misalignment

\begin{abstract}
Damage to the main bearing components on the generator set unit operating in the PLTD to supply power to PLN. Based on the initial indication of engine blow-by and high vibration in the damper area of the service meter unit (SMU): 25555. The purpose of this study is to determine the root cause of the main bearing damage that changes shape and color in the diesel engine generator set. The method used in this research is a visual inspection and removing engine components. The results and discussion of the research obtained changes in the shape and color of the main bearing, starting from the main bearing material (rotating) spalling so that it rubs against the main journal. The friction that occurs causes changes in the shape of the main bearing and causes the main bearing to rotate. The keywords on the main bearing are released due to thinning so that the main bearing rotates and closes the supply of lubricating oil to the main and rod bearings. Based on the analysis, the most likely cause of adhesive wear on Main Bearing \#1 is crankshaft misalignment towards the front of the engine.
\end{abstract}

Keywords: Generator set, Main bearing, Change of shape, Misalignment

How to Cite: Arso, W., 2021, Analisis Kerusakan Main Bearing pada Unit Generator Mitsubishi BMGS, JMEMME (Journal of Mechanical Engineering, Manufactures, Materials and Energy), 5 (2): 151-160. 


\section{PENDAHULUAN}

Pada sebuah Generator set yang dioperasikan untuk suplai daya ke PLN dan mengalami kerusakan pada salah komponen main bearingnya, sedangkan pada saat beroperasinya sesuai dengan kebutuhan daya, maka unit tersebut beroperasi kurang lebih selama 10-15 jam per hari. Jika salah satu unit mengalami kerusakan maka suplai daya berkurang dan mengakibatkan denda penalti secara $\mathrm{kWH}$.

Pada kegiatan service meter unit (SMU) 25554, unit stop karena terjadi kebocoran atau rembesan oli dari supply line tube poros turbo kiri. Selanjutnya dilakukan perbaikan oleh operator dengan kronologis pada unit generator set diperlihatkan tabel 1.

Tabel 1. Histori perawatan unit generator set

\begin{tabular}{cl}
\hline Waktu & \multicolumn{1}{c}{ Keterangan pekerjaan } \\
\hline Pukul 11:00 & Perbaikan kebocoran oli dengan mengganti gasket 1 pc. \\
Pukul 13:15 & $\begin{array}{l}\text { Test running dan on system dengan beban bertahap sampai dengan } \\
\text { 1000 kW }\end{array}$ \\
Pukul 14:20 & $\begin{array}{l}\text { SMU 25555 Unit stop kembali karena masih terjadi rembesan pada } \\
\text { tempat yang sama. }\end{array}$ \\
\hline
\end{tabular}

Pada saat leader operator melakukan start up unit untuk memastikan lokasi dan kondisi kebocoran, unit mengalami vibrasi tinggi pada area vibration damper (Front side) dan terjadi blow by, sehingga unit distop kembali dengan melakukan emergency stop. Dari pemeriksaan yang dilakukan didapatkan temuan failure parts, 1) Connecting rod Bearing \#1 \& \#9 spinning dan heavy scratch, 2) Main Bearing \#1 spinning dan heavy scratch pada lower bearing, 3) Crankshaft heavy scratch pada Rod journal \#1 \& \#9 dan Main journal \#1. 4) Cylinder block pada bore main bearing \#1 scratch, 5) Bore connecting rod \#9 scratch, 6) Cylinder pack \#1 (Piston retak dan scratch, cylinder liner heavy scratch).

Kerusakan terjadi pada komponen main bearing yang mengalami scratch [1]. Material main bearing yang terkelupas bergesekan dengan crankshaft. Pada saat main bearing berputar dan menutup suplai oli menuju crankshaft, mengakibatkan tertutupnya suplai pelumasan di satu silinder dan menyebabkan perubahan warna pada main bearing dikarenakan tidak ada pelumasan.

Untuk mempelajari karakteristik pelumasan bearing utama untuk mesin diesel pada kondisi deformasi elastis, maka dibuat model simulasi dinamika fluida elastis bearing utama mesin diesel [2]. Data gaya bantalan untuk bantalan utama mesin diesel dalam kondisi terukur dan kondisi salah tembak silinder 1 dianalisis, untuk memberikan dasar bagi desain tribologi pasangan gesekan bantalan utama dan optimalisasi sistem mesin diesel [3]. Faktor koreksi khusus yang bergantung pada komposisi kimia bahan bakar diusulkan untuk menormalkan diameter bekas luka keausan rata-rata [4].

Pemeriksaan bearing utama harus dilihat secara keseluruhan dari proses kerja generator set. Poros engkol, yang mengubah gerakan bolak-balik piston menjadi gerakan berputar, harus menahan tegangan lentur yang disebabkan oleh gaya dorong batang penghubung saat piston berada di tengah atas. Kemudian tekanan gas maksimum bekerja 
lurus ke bawah pada crankpin dan cenderung menekuk poros di antara bantalan yang berdekatan. Rankshaft juga harus menahan gaya puntir yang dihasilkan oleh perubahan kecepatan.

Ketika bantalan diperiksa, penampilan bantalan harus dicatat terlebih dahulu dan jumlah serta kondisi pelumas sisa harus diperiksa. Setelah pelumas diambil sampelnya untuk diperiksa, bantalan harus dibersihkan. Secara umum, minyak ringan atau minyak tanah dapat digunakan sebagai larutan pembersih.

Bantalan yang dilepas pertama-tama harus dibersihkan terlebih dahulu diikuti dengan pembilasan akhir. Setiap bak harus dilengkapi dengan jaring logam untuk menopang bantalan dalam minyak tanpa menyentuh sisi atau bagian bawah tangki. Jika bantalan diputar dengan benda asing di dalamnya selama pembersihan awal, jalur balapan mungkin rusak. Pelumas dan endapan lainnya harus dihilangkan dalam penangas minyak selama pembersihan kasar awal dengan sikat atau cara lain.

Setelah dibersihkan secara menyeluruh, bantalan harus diperiksa untuk kondisi lintasan dan permukaan luarnya, jumlah keausan sangkar, peningkatan jarak bebas internal, dan penurunan toleransi. Ini harus diperiksa dengan hati-hati, selain pemeriksaan untuk kemungkinan kerusakan atau kelainan lainnya, untuk menentukan kemungkinan penggunaan kembali.

Beberapa penelitian telah dikerjakan dengan topik bahan-bahan alternatif pengganti rumah bearing. Bahan Komposit adalah bahan polimer laminasi yang dibuat dengan memenuhi tekstil dengan resin termoset. Sifat fisik bahan komposit menjadikannya bahan bantalan yang unggul [5]. Komposit menawarkan rekayasa desain alternatif yang menarik dan hemat biaya untuk bahan tradisional yang digunakan untuk busing, bantalan, bantalan aus, dan mesin cuci dorong [6].

Bahan komposit memiliki koefisien gesekan yang lebih rendah daripada perunggu dalam situasi statis dan dinamis. Adalah umum untuk mencapai koefisien gesekan 50\% lebih rendah saat transisi ke komposit. Bantalan perunggu menimbulkan risiko kontak logam dengan logam jika gemuk tidak ada atau tidak cukup untuk menopang poros, dan dapat menimbulkan persyaratan torsi pemutusan yang tinggi setelah periode istirahat yang lama [7, 8]. Bahan komposit dilumasi sendiri, meminimalkan masalah dengan sistem pelumasan, khususnya dalam beban tinggi, kecepatan lambat, atau aplikasi berosilasi. Bahan komposit mampu menghilangkan masalah stick-slip yang bising, memperpanjang umur pengoperasian dan mengurangi keausan, sehingga menghasilkan efisiensi pengoperasian yang lebih baik [9].

Tujuan dari penelitian ini adalah untuk menentukan akar penyebab dari kerusakan main bearing pada diesel engine, agar kerusakan yang sama, tidak terulang kembali. Adapun tempat penelitian dilakukan di PLTD Senggiring-Lombok Barat.

\section{METODE PENELITIAN}

Dalam metode penelitian kerusakan main bearing, dilakukan untuk mengetahui akar penyebab kerusakan yang terjadi. Metode ini untuk memudahkan dalam proses analisis komponen, dan membatasi setiap komponen yang dianalisis. 1) Identifikasi 
masalah terhadap kerusakan main bearing yang mengakibatkan tidak beroperasional unit pembangkit yang berakibat penurunan suplai daya ke PLN. 2) Pengumpulan data pendukung dilakukan dengan cara inspeksi lapangan dan pengambilan data operasi. 3) Melakukan investigasi dan identifikasi masalah, pemeriksaan secara visual yang dilakukan dengan melakukan pemeriksaan secara umum dan langsung pada material yang mengalami kerusakan. 4) Pemeriksaan visual dengan melakukan pemeriksaan secara langsung terhadap material main bearing dan crankshaft. Pengamatan visual ini penting dilakukan sebelum melakukan pengujian yang lebih detail. Karena untuk mendeteksi adanya cacat pada permukaan main bearing. Pengamatan visual ini penting dilakukan untuk menentukan langkah pemeriksaan berikutnya dari pola kerusakan yang terjadi. 5) Pengambilan sampel uji untuk pengujian material dilakukan pada main bearing yang mengalami kerusakan dan yang normal. 6) Dalam mendukung penelitian ini dilakukan pengujian komposisi kimia, pengujian metalografi. Alat yang dipergunakan dalam melakukan penelitian di antara standar tools kerja untuk melepas main cap, rod bearing, main bearing, adapun bahan penelitian adalah main bearing unit Mitsubishi.

Alat untuk mendokumentasikan dalam penelitian menggunakan kamera, dimana alat ini harus mempunyai resolusi yang tinggi, supaya mendapatkan hasil gambar cukup jelas, sesuai gambar 1 [10]. Adapun gambar 2 bahan penelitian berupa komponen main bearing yang mengalami perubahan warna dan bentuk.

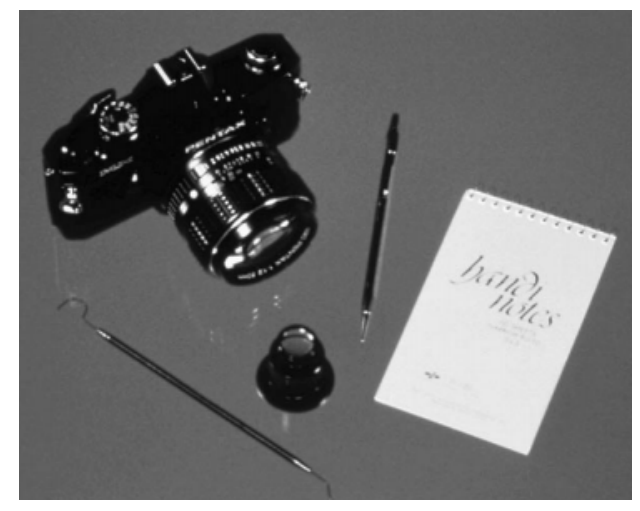

Gambar 1. Kamera resolusi yang tinggi

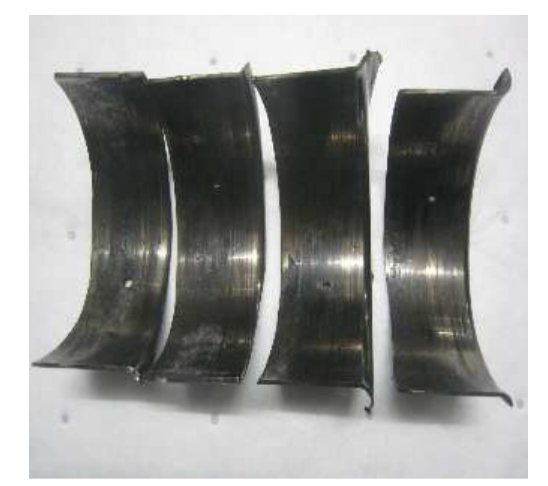

Gambar 2. Komponen main bearing 


\section{HASIL DAN PEMBAHASAN}

Kerusakan terjadi setelah beroperasi 70 jam dari PM 1 atau 1736 jam dari last TOH (Top overhaul), atau sama dengan 6184 jam dari GOH (General Overhaul), investigasi problem dilakukan diantaranya, 1) Melakukan pengecekan pada filter oli (untuk mengetahui partikel yang tersaring pada filter, apakah dalam bentuk logam maupun non logam). 2) Melakukan pengecekan rod bearing secara acak, untuk mengetahui di silinder yang mengalami kerusakan major, 3) Melakukan pengecekan main bearing sesuai kerusakan yang cukup parah pada rod bearing.

Data DAR (daily activity record) selama 3 hari terakhir pada unit ini tercatat baik, hampir seluruh parameter terekam normal, hanya exhaust temperatur cylinder \#1 dan \#16 lebih tinggi dari cylinder lain. Data SOS terakhir yang diambil saat PM250 (Preventive maintenance 250) dan 2 sample sebelumnya menunjukkan evaluasi A [11], tidak ada parameter yang menunjukkan keausan berlebih yang dijelaskan pada tabel 2 .

Tabel 2. Data pengujian sampel oli.

\begin{tabular}{ccccccccccccccccccccccccccccccc}
\hline Eval & Mo & $\mathrm{Cr}$ & $\mathrm{Zn}$ & $\mathrm{Pb}$ & $\mathrm{Fe}$ & $\mathrm{Si}$ & $\mathrm{Mg}$ & $\mathrm{Sn}$ & $\mathrm{Cu}$ & $\mathrm{Al}$ & $\mathrm{Ni}$ & $\mathrm{Ca}$ & $\mathrm{Na}$ & $\mathrm{K}$ & $\mathrm{B}$ & $\mathrm{P}$ & $\mathrm{ST}$ & OXI & $\mathrm{NIT}$ & SUI & $\mathrm{W}$ & $\mathrm{FP}$ & $\mathrm{V} 100$ & $\mathrm{TBN}$ & $\mathrm{GF}$ & PQ \\
\hline $\mathrm{A}$ & 0 & 1 & 1173 & 8 & 17 & 3 & 11 & 1 & 1 & 2 & 0 & 3567 & 4 & 0 & 241 & 973 & 17 & 22 & 11 & 27 & $\mathrm{~N}$ & $\mathrm{~N}$ & 13.93 & 7.2 & $\mathrm{~N}$ & 0 \\
$\mathrm{~A}$ & 0 & 1 & 1671 & 10 & 22 & 3 & 17 & 0 & 1 & 2 & 0 & 4945 & 5 & 0 & 551 & 1632 & 18 & 22 & 11 & 29 & $\mathrm{~N}$ & $\mathrm{~N}$ & 14.34 & 7.52 & $\mathrm{~N}$ & 0 \\
$\mathrm{~A}$ & 0 & 2 & 1418 & 6 & 27 & 5 & 13 & 1 & 2 & 3 & 0 & 4172 & 4 & 0 & 453 & 1214 & 18 & 21 & 11 & 26 & $\mathrm{~N}$ & $\mathrm{~N}$ & 14.07 & 7.49 & $\mathrm{~N}$ & 0 \\
\hline
\end{tabular}

Unit mengalami perbaikan pada cylinder pack 11 dan 16 oleh mekanik, tercatat 7 kali engine start-stop dengan interval kurang lebih 15 menit. Stop unit dilakukan karena setting rack actuator yang berulang-ulang terutama di sisi kiri.

Pada gambar 3 connecting rod journal \#1 scratch dan terjadi perubahan warna (discoloration) dan tampak hangus akibat efek panas yang disebabkan tidak ada pelumasan [12].

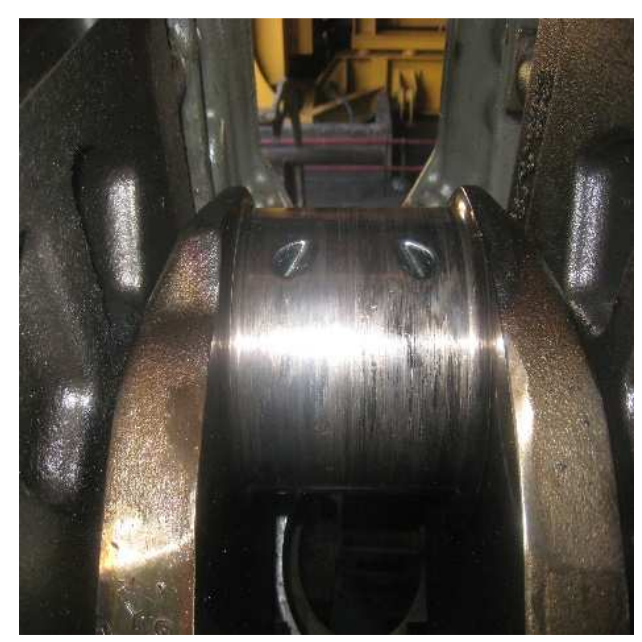

Gambar 3. Rod journal scratch

Main journal pada silinder \#1 mengalami scratch yang diakibatkan oleh gesekan dengan material bearing yang terlepas dari permukaan, sesuai dengan gambar 4 . 


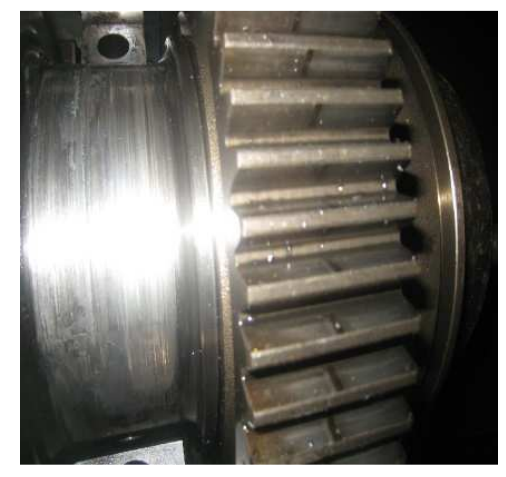

Gambar 4. Scratch pada main journal \#1

Pada gambar 5 komponen connecting rod bearing \#1 dan \#9 smelted dan tampak hangus. Material back steel mengalami perubahan warna, dimana hal menandakan titik tersebut mendapatkan efek panas saat terjadi gesekan dengan crankshaft.

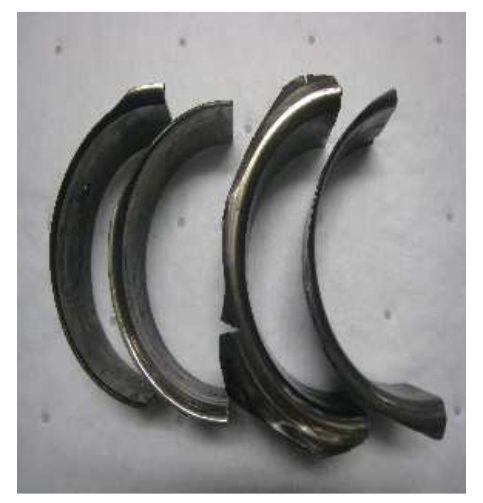

Gambar 5. Main bearing smelted dan discoloration

Gambar 6 komponen cap connecting rod \#1 scratch dan tampak hangus, dan menimbulkan perubahan warna. Mengindikasi terjadi bearing (spinning) dan menandakan titik tersebut mendapatkan efek panas yang tidak ada pelumasan pada komponen cap connecting rod \#1 [13].

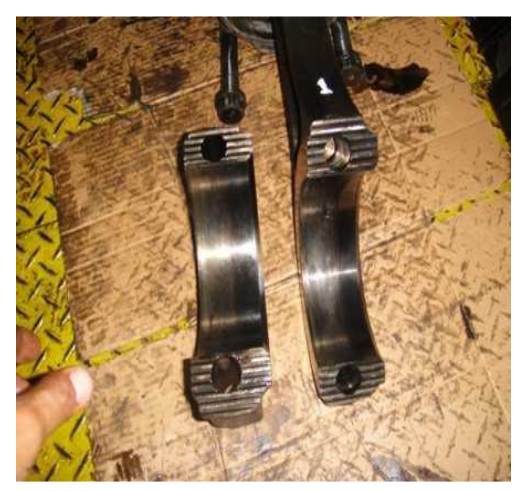

Gambar 6. Perubahan warna pada cap conrod

Sedangkan gambar 7 komponen main bearing \#1 scratch dan spinning. Pada bagian bawah (lower) bearing scratch dalam. Scratch pada main bearing ini terjadi karena 
diakibatkan gesekan dengan material main bearing yang lepas tanpa adanya pelumasan (spalling) [14].

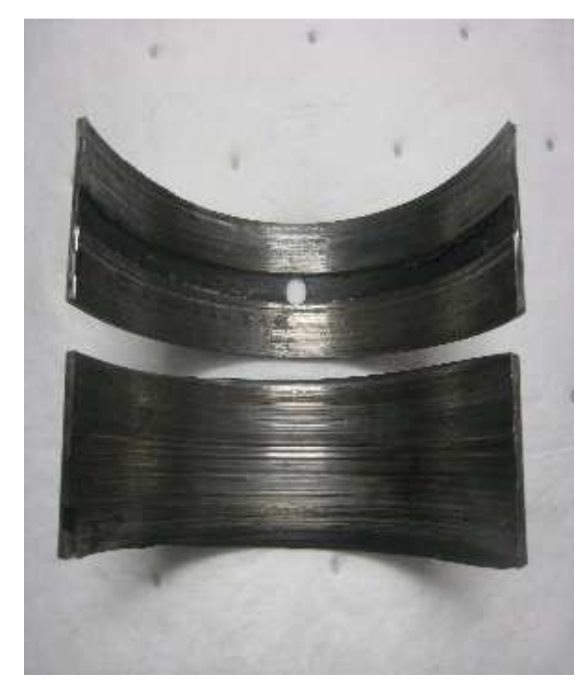

(a)

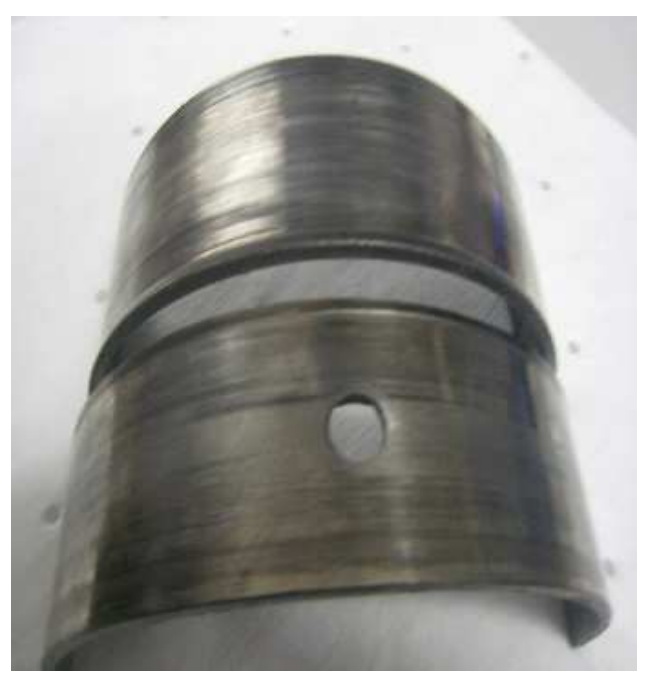

(b)

Gambar 7. Perubahan bentuk pada back steel: (a) bagian dalam, dan (b) bagian luar [15]

Kemudian gambar 8 dudukan main bearing \#1 scratch dan terdapat key lock lower main bearing masih berada di groove. Dimana saat unit masih beroperasi main bearing berputar tanpa key lock yang menempel pada main bearing hal ini yang mengakibatkan perubahan bentuk komponen main bearing dan berputarnya main bearing yang mengakibatkan suplai oli ke komponen rod bearing tidak ada.

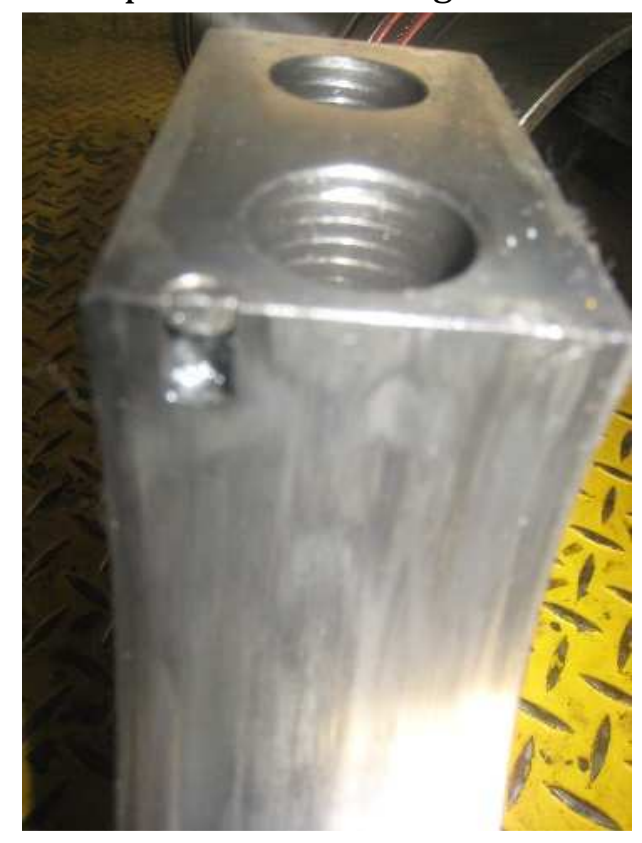

Gambar 8. Scratch dan perubahan bentuk pada main cap

Gambar 9 komponen body piston \#1 crack dan scratch yang disebabkan oleh gesekan dengan liner, saat terjadi unbalance putaran crankshaft, yang disebabkan komponen main bearing sudah mengalami perubahan bentuk. 


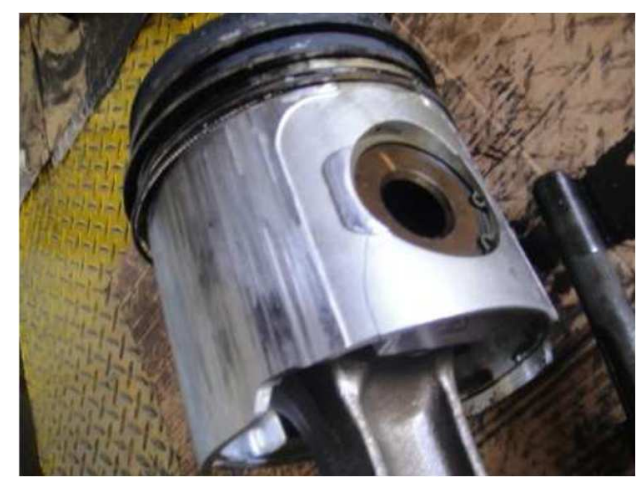

Gambar 9. Piston scratch

Gambar 10 komponen cylinder liner \#1 scratch yang dikarenakan bergesekan dengan piston, dimana material dari ring piston patah dan bergesekan dengan dinding liner, hal diakibatkan saat terjadi perubahan bentuk pada main bearing, sehingga pergerakkan piston saat dari TMB maupun TMA terjadi unbalance, yang mengakibatkan piston bergesekan dengan liner.

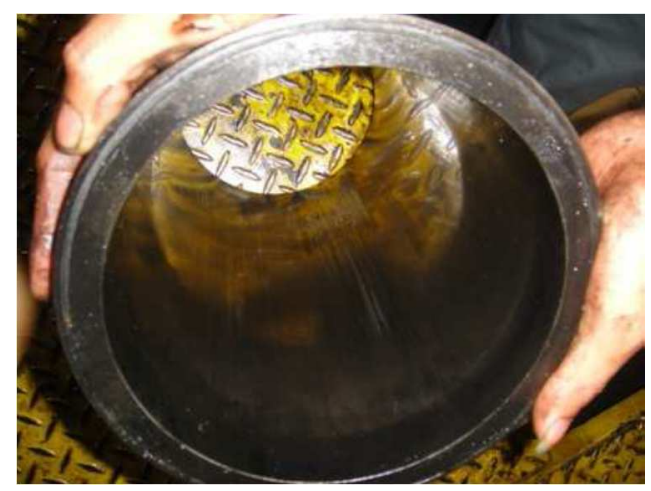

Gambar 10. Dinding liner scratch

Secara visual pada crankshaft terjadi heavy scratch dan discoloration pada rod journal \#1 \& \#9 dan partial scratch (1/3 bagian) main journal \#1, sedangkan pada main journal \#2 s/d \#8 \& Rod Journal \#2 s/d \#16 normal.

Connecting rod bearing \#1 \& \#9 heavy scratch dan spinning, Main bearing \#1 scratch sedangkan main dan conrod bearing lainnya normal. Pada dudukan main bearing \#1, terdapat key lock main bearing yang tertinggal, dan cylinder pack \#1, liner scratch dan body piston scratch dan crack.

Berdasarkan fakta dari kerusakan part cylinder pack, conrod bearing, main bearing dan crankshaft diatas hal ini menandakan bahwa telah terjadi problem overheating individual pada cylinder pack \#1. Terjadinya temperatur berlebih pada cylinder pack ini akibat adanya gangguan pelumasan ke body piston yang disebabkan terhambatnya supply oli akibat rusaknya connecting rod bearing.

Dari gambar 3 terlihat bahwa conrod jurnal mengalami keausan adhesive. Kerusakan ini terjadi saat temperatur permukaan terlalu tinggi sehingga lapisan lead-tin dan lapisan aluminium mencair dan menempel pada crankshaft. Proses keausan adhesive 
pada conrod bearing dimulai dengan proses polishing lapisan tin flash [16]. Saat temperatur bertambah, lapisan lead-tin segera meleleh dan membentuk lipatan melebar kemudian terus berlanjut sampai back steel dan akan menyebabkan gaya dari seizure (lengket) [17] menjadi lebih besar dari pada gaya crush sehingga bearing akan menempel pada crankshaft dan berputar dalam bore yang mengakibatkan rod journal heavy scratch (gambar 3). Kerusakan ini mengakibatkan suplai oli untuk mendinginkan dan melumasi cylinder pack menjadi berkurang ini terbukti terjadinya crack pada body piston dan scratch pada dinding cylinder liner (gambar 8) yang menyebabkan blow by, sesuai dengan keterangan dari operator yang bertugas.

Tingginya temperatur permukaan pada rod journal dan conrod bearing \#1 \& \#9 karena tidak mendapat pelumasan akibat tersumbatnya supply oli dari main oil gallery yang disebabkan oleh bergesernya posisi main bearing \#1 sehingga menutup hole oil line (gambar 7) [18].

Main bearing \#1. bergeser posisinya ditandai dengan terjadi kerusakan adhesive wear dan back steel terlihat zinc dan tertinggalnya key lock lower bearing dan covernya (gambar 6). Kronologis operator juga menyatakan vibrasi tinggi bermula dari bagian depan engine (vibration damper), yang disebabkan oleh main bearing \#1 spinning.

\section{KESIMPULAN}

Dari analisa dan fakta-fakta diatas, disimpulkan bahwa terjadinya individual problem pada Main Bearing no 1 ini diawali dengan lepasnya key lock dan bearing bergeser sehingga pelumasan berkurang, sehingga terjadi adhesive wear dan selanjutnya main bearing mengalami spinning, yang berakibat tertutupnya hole oil line dari main oil gallery sehingga pelumasan ke rod journal tidak dapat teraliri dan menyebabkan kurangnya pelumasan di rod journal. Hal ini ditunjukkan dengan kerusakan parah pada conrod journal dan con rod bearing \#1 \& \#9. Penyebab dari adhesive wear pada Main Bearing \#1 yang paling memungkinkan adalah misalignment crankshaft ke arah depan engine. Hal ini ditunjukkan oleh jejak wear yang tidak terlihat di main journal di seluruh permukaan, namun hanya sebagian saja (gambar 5). Main bearing \#1 bagian bawah menunjukkan terjadi tekanan yang diakibatkan oleh journal crankshaft yang bersentuhan dengan bearing, khususnya di area depan kiri, dimana terlihat deformasi lebih pada bearing bagian tersebut.

\section{UCAPAN TERIMAKASIH}

Kami ucapkan banyak terima kasih kepada STTMC yang telah membiayai dalam hal penelitian dan Lembaga Penelitian, Pengabdian kepada Masyarakat yang telah memberikan arahan dari mulai persiapan penelitian, serta sampaikan dengan Publikasi artikel. 


\section{REFERENSI}

[1] A. Tauqir, I. Salam, A. ul Haq and A. Khan, "Causes of fatigue failure in the main bearing of an aeroengine," Engineering Failure Analysis, vol. 7, no. 2, pp. 127-144, 2000.

[2] A. Wang, S. An and T. Nie, "Analysis of Main Bearings Lubrication Characteristics for Diesel Engine," in Materials Science and Engineering, Beijing, 2019.

[3] G. . L. N. Liu and Z. Zheng, "Analysis of diesel engine main bearing lubrication under single-cylinder misfiring situation," Journal Metric, vol. 8, no. 1, p. 85-90, 2015.

[4] E. S. M. Lapuerta and J. S. Valdepeñas, "Effect of ambient humidity and hygroscopy on the lubricity of diesel fuels," Engineering Science and Technology, vol. 9, no. 1, pp. 30-39, 2013.

[5] M. Y. Yuhazri, A. J. Zulfikar and A. Ginting, "Fiber Reinforced Polymer Composite as a Strengthening of Concrete Structures: A Review," in 2nd International Conference in Industry and Manufacture Engineerin, Medan, 2020.

[6] A. J. Zulfikar, "The Flexural Strength of Artificial Laminate Composite Boards made from Banana Stems," Budapest International Research in Exact Sciences (BirEx) Journal, vol. 2, no. 3, pp. 334340, 2020.

[7] A. J. Zulfikar and M. Y. R. Siahaan, "Analisis Signifikansi Roda Skateboard Berbahan Komposit Serbuk Batang Pisang Terhadap Perfoma Kecepatan Dengan Metode Anova," Jurnal Rekayasa Material, Manufaktur dan Energi, vol. 4, no. 2, pp. 83-90, 2021.

[8] A. J. Zulfikar, A. Sofyan and M. Y. Siahaan, "Numerical Simulation on The Onion Dryer Frame Capacity of 5 kg/hour," JMEMME (Journal of Mechanical Engineering Manufactures Materials and Energy), vol. 2, no. 2, p. 86-92, 2018.

[9] A. J. Zulfikar, B. Umroh and M. Y. R. Siahaan, "Design and manufacture of skateboard from banana stem," JMEMME (Journal of Mechanical Enggineering, Manufactures, Materials and Energy), vol. 3, no. 2, pp. 109-116, 2019.

[10] S. NAGAI, K. YAMAZAKI, M. TSUMORI and Y. TAKAHASHI, "Construction of multi-directional high-speed imaging system using a streak camera and image compression method," High Energy Density Physics, vol. 7, no. 1, pp. 54 - 72, 2020.

[11] W. Wilarso, A. Surya, D. N. Adnyana and K. Koswara, "Damage Analysis of The Electric Generator Diesel Engine Connecting Rod," in Journal of Physics: Conference Series, Jakarta, 2020.

[12] E. Febriyanti, "ANALISA KERUSAKAN CONNECTING ROD PADA MESIN DIESEL KENDARAAN BERMOTOR," Jurnal Sains dan Teknologi Indonesia, vol. 12, no. 3, pp. 214-219, 2020.

[13] W. Wilarso, A. Domodite, H. Sholih and M. Mujiarto, "Analysis of SOS Results for Engine Lubricants Contaminated by the Fuel in the 3516 TA Diesel Engine Generator Set," in Journal Physics: Conference series, Jakarta, 2021.

[14] I. Qureshia, N. Ejazb, S. Rizvi and M. Farooque, "Failure Analysis of Engine Bearing," Key Engineering Materials, vol. 510, no. 1, pp. 513-519, 2012.

[15] S. A. J. Jahromi, M. M. Goudarzi and A. Nazarboland, "Failure analysis of GE-F9 gas turbine journal bearings," Iran Journal Science E Technology, vol. 32, no. 1, p. 61-66, 2008.

[16] A. Vencl, V. Gašić and B. Stojanović, "Fault tree analysis of most common rolling bearing," in 13th International Conference on Tribology, Belgrade, 2017.

[17] D. W. Gebretsadik, J. Hardell and B. Prakash, "Seizure behaviour of some selected Pb-free engine bearing materials under lubricated condition," Tribology International, vol. 111, no. 1, pp. 265275, 2017.

[18] H. Shahmohamadi, R. Rahmani, H. Rahnejat, C. P. Garner and D. Dowson, "Big End Bearing Losses with Thermal Cavitation Flow Under Cylinder Deactivation," Tribol Lett, vol. 57, no. 2, pp. 217, 2015. 